\title{
Use of autologous pleural flap buttress in thoracoscopic lung volume reduction surgery
}

\author{
Yung-Chie Lee, MD, PhD, ${ }^{a}$ Yih-Leong Chang, MD, ${ }^{b}$ Chung-Wei Chen, MD, ${ }^{a}$ Nai-Chuan Chien, MD, ${ }^{a}$ and \\ Pei-Ming Huang, MD, ${ }^{\text {a }}$ Taipei, Taiwan
}

$\mathrm{L}$

ung volume reduction surgery (LVRS) has been considered an effective procedure for improvement of pulmonary function in cases of severe emphysema with appropriate patient selection. ${ }^{1,2}$ Air leakage from the staple line after resection of the emphysematous lung has been a major complication after LVRS. ${ }^{1}$ Several techniques, with fibrin glue, bovine pericardial strip buttressing, ${ }^{3}$ fold plication, ${ }^{4}$ or polyglycolic acid felt buttressing, ${ }^{5}$ have been developed to prevent this postoperative air leakage. Although these techniques substantially reduce major, prolonged, or both air leakages, disadvantages include incorporation of foreign materials and cost. We have recently developed a new technique using an autologous pleural flap to buttress the staple line. The new procedure is simple, effective, and cost free, and it might enhance pleural adhesion after surgical intervention.

\section{Clinical Summary}

A 62-year-old man who had been a heavy smoker (one pack per day for 50 years) had progressive exertional dyspnea for 5 years before admission. Chronic obstructive pulmonary disease was diagnosed on the basis of chest radiography and spirometry examination. Despite regular use of oral and inhalational bronchodilators and oral prednisolone at the outpatient clinic, the dyspnea symptoms had worsened. After admission, the functional class was assessed as World Health Organization class III, and the patient was mostly confined to bed with nasal oxygen support. The spirometry study revealed a forced vital capacity of $2.52 \mathrm{~L}(82.3 \%)$, a forced expiratory volume in 1 second $\left(\mathrm{FEV}_{1.0}\right)$ of $0.69 \mathrm{~L}$ (28.3\%), a percent $\mathrm{FEV}_{1.0}$ of $27.4 \%$, a residual volume of $3.7 \mathrm{~L}$ $(236.3 \%)$, a total lung capacity of $6.4 \mathrm{~L}(137.4 \%)$, and a maximum voluntary ventilation of $17.9 \mathrm{~L} / \mathrm{min}(22.8 \%)$. Diffusion capacity was $8.7 \mathrm{~mL} \cdot \min ^{-1} \cdot \mathrm{mm} \mathrm{Hg}^{-1}(47.6 \%)$. The pulmonary exercise maximum oxygen consumption was $13.1 \mathrm{~mL} \cdot \min ^{-1} \mathrm{~kg}^{-1}$ $(43.3 \%)$. Chest computed tomography showed diffuse emphysematous changes with bulla formation, which was more severe on

From the Division of Thoracic Surgery, the Departments of Surgery ${ }^{\mathrm{a}}$ and Pathology, ${ }^{\mathrm{b}}$ National Taiwan University Hospital and National Taiwan University College of Medicine, Taipei, Taiwan.

Received for publication Oct 28, 2002; accepted for publication Nov 21, 2002.

Address for reprints: Yung-Chie Lee, MD, PhD, Department of Surgery, National Taiwan University Hospital, No. 7 Chung-Shan South Rd, Taipei, Taiwan (E-mail: wuj@ha.mc.ntu.edu.tw).

J Thorac Cardiovasc Surg 2003;126:298-9

Copyright (C) 2003 by The American Association for Thoracic Surgery $0022-5223 / 2003 \$ 30.00+0$

doi:10.1016/S0022-5223(03)00085-0 the bilateral upper lobes. Ventilation scans revealed heterogenous tracer ventilation in bilateral lung fields, and arterial blood gas on room air was $\mathrm{pH} 7.39, \mathrm{PaO}_{2}$ was $78.5 \mathrm{~mm} \mathrm{Hg}, \mathrm{PaCO}_{2}$ was $38.5 \mathrm{~mm}$ $\mathrm{Hg}$, and $\mathrm{HCO}_{3}^{-}$was $22.8 \mathrm{mEq} / \mathrm{L}$. The patient was deemed a good candidate for LVRS, with the new technique subsequently used during the operation.

LVRS was performed by the bilateral thoracoscopic approach. First, a left-sided double-lumen tube was inserted to provide unilateral lung collapse during the thoracoscopic procedure. The patient was placed in the true lateral position, with his right side upward. A camera port $(1 \mathrm{~cm})$ was first made in the ninth intercostal space (ICS) along the midaxillar line. After inspection of lung pathology, a 3-cm working port was made in the third ICS in the midsubaxillar area, without entrance into the parietal pleura. Another 1-cm working port was made subsequently in the fifth ICS along the anterior-axillar line. Blunt dissection was commenced on the first working port, with the dissection plane between the parietal pleura and chest wall. Dissection of a large flap of parietal pleura was very simple because the interior between the parietal pleura and chest wall consisted only of areolar tissue (Figure 1, $a$ ). The area of dissection was anterior to the mediastinum, posterior to the paraspinal area, and extended downward to the fifth ICS, which was carefully preceded to avoid injury to the sympathetic trunk and intercostal vessels. Subsequently, a pleural flap (approximately $15 \times 15 \mathrm{~cm}^{2}$ ) was dissected out (Figure 1, $b$ ). The flap was cut into several $8 \times 1.2-\mathrm{cm}^{2}$ strips, which were separately tied on both sides of the staple machine (Figure 1,c) with this autologous pleural buttress staple. In total, $20 \%$ to $30 \%$ of the lung tissue was removed (Figure 1, d). Finally, a single chest tube was inserted. The patient was then turned to the right decubitus position, and the same procedure was performed for the left lung. Four sets of endo-GIA-2 staples $(60 \times 4.8 \mathrm{~mm}$, United States Surgical Corp) were used for each side. The total duration of the operation was 4 hours and 30 minutes.

\section{Results}

There was no air leakage from the bilateral chest tubes after the operation. The patient was extubated on the second day after the operation and transferred to the general ward 1 day later. The chest tubes were removed on the fifth day. Recovery was uneventful, and the symptom of exertional dyspnea gradually improved. The patient was finally discharged 8 days after the operation. Follow-up spirometry 1 month after the operation revealed a forced vital capacity of $2.33 \mathrm{~L}$ (76.1\%), an $\mathrm{FEV}_{1.0}$ of $0.91 \mathrm{~L}(37.0 \%)$, and a maximum voluntary ventilation of $29.0 \mathrm{~L} / \mathrm{min}$ (36.9\%). Functional class had improved to World Health Organization class II.

\section{Discussion}

Air leakage remains a cause of major postoperative morbidity after LVRS. Pulmonary function might deteriorate, resulting in prolonged 

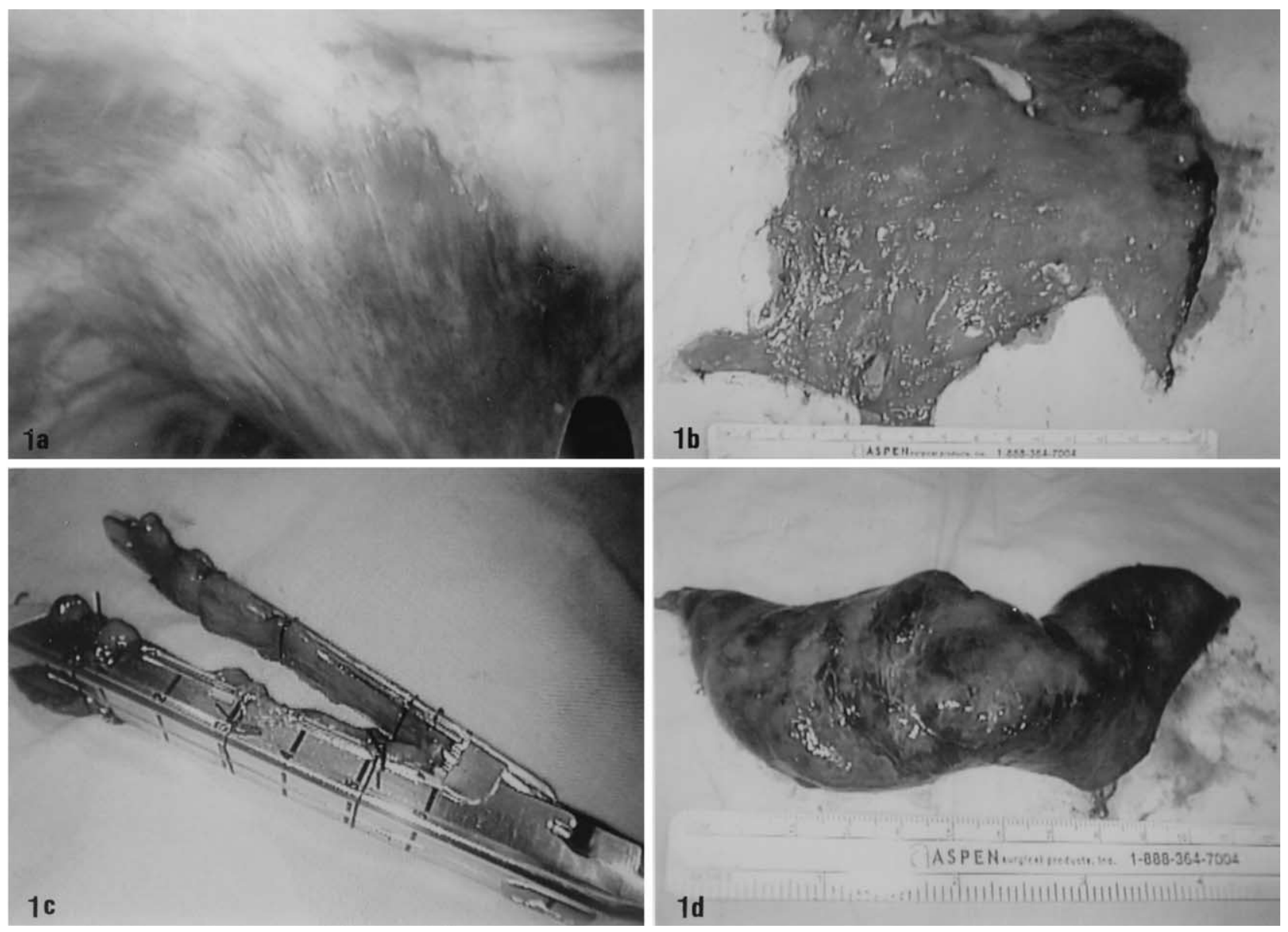

Figure 1. a, Viewing though a thoracoscopic camera, a broad piece of parietal pleura was dissected downward. b, A piece of parietal pleura (about $15 \times 15 \mathrm{~cm}^{2}$ ) was taken out. $c$, Parietal pleural strips $\left(8 \times 1.2 \mathrm{~cm}^{2}\right)$ were separated and tied on both sides of the staple machine. $d$, Emphysematous lung tissue was resected from the apical portion of the left lung.

endotracheal intubation, ventilator use, and hospital stay. Furthermore, a few patients have died as a result of this complication. Several techniques have been advocated to reduce incidence. The most widely used variant, developed by Cooper and colleagues, ${ }^{1}$ is bovine pericardial strip buttress of the staple line. In the follow-up report, the results of this technique were reviewed for 150 patients with severe emphysema. Prolonged air leakage ( $>7$ days) still occurred in $46 \%$ of the patients, however, with 6 requiring further surgical procedures, although the air leakage eventually stopped for most of them. In our hospital the bovine pericardial strip is not used for LVRS because it is considered too expensive. Intraoperative mechanical pleurodesis is routinely performed, and minocycline chemical pleurodesis is performed if postoperative air leakage persists beyond 3 days.

The newly developed autologous pleural flap technique has 3 advantages. First, because the material is autologous, tissue healing should be improved. Second, the technique is actually a parietal pleurectomy, which has been considered to be more effective for pleural adhesion, with associated reductions in the duration of air leakage where the complication does occur. Third, there is no additional cost for the buttress. However, the operation time is somewhat prolonged for about 2 hours, although this does not affect the outcome of the patient. Although the initial result is encouraging, more experience is required to verify the efficacy and safety of the procedure.

\section{References}

1. Cooper JD, Patterson GA, Sundaresan RS, Trulock EP, Yusen RD, Pohl MS, et al. Result of 150 consecutive bilateral lung volume reduction procedures in patients with severe emphysema. $J$ Thorac Cardiovasc Surg. 1996;112:1319-29.

2. Criner GJ, Cordova FC, Furukawa S, Kuzma AM, Travaline JM, Leyenson V, et al. Prospective randomized trial comparing bilateral lung volume reduction surgery to pulmonary rehabilitation in severe chronic obstructive pulmonary disease. Am J Respir Crit Care Med. 1999;160:2018-27.

3. Cooper JD. Technique to reduce air leaks after resection of emphysematous lung. Ann Thorac Surg. 1994;57:1038-9.

4. Kuwahira I, Iwasaki M, Kaga K, Iwamoto T, Tazaki G, Ishii M, et al. Effectiveness of the fold plication method in lung volume reduction surgery. Intern Med. 2000;39:381-4.

5. Kawamura M, Kase K, Sawafuji M, Watanabe M, Horinouchi H, Kobayashi K. Staple-line reinforcement with a new type of polyglycolic acid felt. Surg Laparosc Endosc Percutan Tech. 2001;11:43-6. 